\title{
Warum dieses Buch?
}

\section{Zwischen Wunsch und Wirklichkeit liegt die Tat!}

Viel wurde bereits über Projektmanagement und Einkauf geschrieben. Warum nun dieses Buch?

Mit diesem Buch möchte ich nicht nur meinen Seminarteilnehmern, sondern auch den Lesern ein einfaches Werkzeug an die Hand geben, welches sie unterstützen soll, die Herausforderungen der Projekte im Einkauf leichter zu meistern - einen roten Faden und einen „Werkzeugkasten“ für den Alltag. Eine „Toolbox“, auf die in der Hektik des Alltagsgeschäftes immer wieder zurückgegriffen werden kann.

Aus meiner 30-jährigen Erfahrung im Projektgeschäft, basierend auf den nationalen und internationalen Standards des Projektmanagements, sind hier die für mich wichtigsten acht Schritte beschrieben, ohne die es keine Transparenz gibt und damit auch keine Führung im Projekt möglich ist. Je nach Projektart und Umfang können die Schritte in Ausmaß und Tiefe angepasst werden.

In einfacher Reihenfolge geplant und dokumentiert, als Basisplan verankert, ermöglichen sie es mir, Transparenz, schnelle Kommunikation und damit auch eine schnelle Reaktionsgeschwindigkeit in meinem Projekt zu erreichen.

Lange war der Einkauf Dienstleister im Unternehmen. Heute nimmt er eine strategische Rolle ein. Bei immer stärker werdendem Kostendruck und hoher Geschwindigkeit ist das Projektmanagement nicht mehr wegzudenken.

Die Einsparungen im Einkauf liegen schon lange nicht mehr allein in einer gut geführten Verhandlung. Schlagworte wie Total Cost of Ownership, Supply Chain Management, Zentralisierung und Einsparungen durch technologische Anpassungen setzen die Integration vieler Schnittstellen und ein sauber aufgesetztes Prozessmanagement voraus. Die Anforderungen können nur noch bewältigt werden, wenn ein gutes Projektmanagement implementiert ist.

So ist dieses Buch entstanden mit dem Ziel, Projektmanagern in Einkaufsprojekten Hilfestellung für die tägliche Praxis zu geben. Anregungen, Checklisten und Beispielprojekte sollen dabei helfen, den Werkzeugkasten für die tägliche Arbeit zu erweitern.

Die Theorie ist das eine, die Herausforderung im Alltag das andere. Dieses Buch soll darin unterstützen, die Schnittstelle zwischen beiden ein wenig anschaulicher zu gestalten, und neue Anregungen und Sichtweisen für den Arbeitsalltag geben.

(C) Springer Fachmedien Wiesbaden GmbH 2017

K. Hillberg, Projektmanagement im Einkauf, DOI 10.1007/978-3-658-12221-8_1 